Revista de Literatura, História e Memória

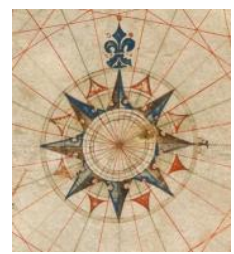

Dossiê: Manifestações de re-existência: a literatura em tempos de repressão

ISSN 1983-1498

VOL. 16 - No 27 - 2020

U N I O E S T E / CA S C A V E L - p. 83-96

\title{
NÃO $\boldsymbol{E} \boldsymbol{S} T \boldsymbol{T}, \boldsymbol{B R} \boldsymbol{A} \boldsymbol{S I L}:$ LITERATURA E HISTÓRIA NO TEMPO DA REPRESSÃO MILITAR
}

Não és tu, Brasil: literature and history in the time of military repression

\author{
Rafael Victor Rosa Oliveira ${ }^{1}$ \\ Felipe dos Santos Matias ${ }^{2}$
}

RESUMO: O presente artigo estuda as interlocuções entre literatura e história no romance Não és tu, Brasil (1996), de Marcelo Rubens Paiva. Nesta obra, o escritor brasileiro, por meio de uma narrativa polifônica e multifacetada, expõe as dificuldades, violências e opressões sofridas por Carlos Lamarca e seus companheiros de Vanguarda Popular Revolucionária (VPR) na luta contra o regime militar da época. Ao produzir um texto literário que adota como tema e enredo um acontecimento histórico, Paiva promove um processo de releitura da história pela literatura, promovendo um diálogo interdisciplinar que possibilita uma ampla reflexão acerca de um dos momentos delicados do Brasil no século XX. O estudo é desenvolvido através da discussão teórico-crítica da obra adotada como corpus, procurandose detectar os modos pelos quais ocorre na narrativa a construção das relações intertextuais entre os elementos históricos e ficcionais.

PALAVRAS-CHAVE: Não és tu, Brasil; Marcelo Rubens Paiva; Literatura; História.

ABSTRACT: This article studies the interlocutions between literature and history in the novel Não és tu, Brasil (1996), by Marcelo Rubens Paiva. In this work, the Brazilian writer, through a polyphonic and multifaceted narrative, exposes the difficulties, violence and oppression suffered by Carlos Lamarca and his companions in the Popular Revolutionary Vanguard (VPR) in the fight against the military regime of the time. When producing a literary text that adopts a historical event as its theme and plot, Paiva promotes a process of re-reading history through literature, promoting an interdisciplinary dialogue that allows for a broad reflection on one of Brazil's delicate moments in the 20th century. The study is developed through the theoretical-critical discussion of the work adopted as a corpus, seeking to detect the ways in which the construction of intertextual relations between historical and fictional elements occurs in the narrative.

KEYWORDS: Não és tu, Brasil; Marcelo Rubens Paiva; Literature; History.

\section{INTERLOCUÇÕES ENTRE LITERATURA E HISTÓRIA}

Desde o século XIX, a história tradicional, sob forte influência do pensamento positivista, faz uso apenas de fontes consideradas "oficiais" para a elaboração da narrativa historiográfica. Tal método, além de ser questionável do ponto de vista tanto material quanto formal - já que suas fontes hegemônicas e homogêneas apresentam uma versão limitada dos acontecimentos -, cristaliza o debate histórico, ao ignorar um conjunto de materiais que

\footnotetext{
${ }^{1}$ Mestrando em Literatura Comparada na Universidade Federal da Integração Latino-Americana. Bolsista DSUNILA. Graduado em Direito pela Faculdade Católica do Tocantins (FACTO).

${ }^{2}$ Doutor em Letras pela Universidade Federal de Juiz de Fora, com período sanduíche na Universidade de Coimbra, Portugal. Professor Adjunto da Universidade Federal da Integração Latino-Americana, atuando na Graduação e no Programa de Pós-Graduação em Literatura Comparada.
} 
poderiam auxiliar na construção de uma história mais ampla e plural.

Alguns estudiosos questionam este positivismo cientificista na historiografia. Entre eles, podemos citar Hayden White, Georges Duby, e Linda Hutcheon, dentre outros. Os referidos autores defenderam uma abordagem pós-estruturalista da história, com o objetivo de denunciar a parcialidade da narrativa historiográfica, construída por meio de um recorte consciente ou inconsciente dos acontecimentos que se desdobraram no passado. Outro aspecto defendido por estes autores foi o de introduzir no debate sobre o tempo pretérito vozes até então ignoradas pela dita "história tradicional", preocupada tão somente com fontes documentais e supostamente imparciais.

Enquanto a história tradicional se baseia em documentos oficiais, isto é, em pontos de vista institucionalizados, muitos historiadores estão cada vez mais preocupados com as opiniões das pessoas comuns e com a história das mentalidades coletivas. Almejam captar a maior quantidade possível de perspectivas. A variedade de vozes e de pontos de vista multiplicam as áreas de atuação e de visão do historiador; são elas que lhe propiciam atacar o mito da objetividade histórica e criticá-la contundentemente. Nesta direção, esta prática aproxima-se do conceito de polifonia de Mikhail Bakhtin, que vislumbra em sua análise da obra de Fiódor Dostoiévski a combinação simultânea de várias vozes e discursos, dentro de uma mesma narrativa.

O conceito de história ao qual estamos acostumados, fundamentado em relações de causa e efeito, de séculos após séculos, é um modelo criado no Ocidente, ou seja, é uma construção cultural com viés ocidental e eurocêntrico. Por isso, é importante ressaltar que a própria ideia de "cultura" - diferente do que se pensava no passado, isto é, de que ela apenas refletia uma realidade - passou a ser considerada tanto como um produto do seu meio quanto produtora de significados e símbolos.

Desde Aristóteles, na Antiguidade, convencionou-se diferenciar os fenômenos ditos históricos daqueles considerados ficcionais, restringindo o papel do historiador a ocupar-se de eventos atribuídos a situações específicas no tempo e no espaço, acontecimentos estes supostamente observáveis e perceptíveis, enquanto que o escritor de ficção se ocuparia de eventos a partir da imaginação e de casos possíveis ou inventados.

Essa cisão, reforçada pelo pensamento positivista do século XIX, estabeleceu uma dicotomia entre o que é a história e o que é a literatura. À primeira, caberia narrar o ocorrido de fato, ao passo que a segunda se ocuparia em relatar o que porventura poderia ter acontecido. Logo, o historiador andaria no encalço de uma "verdade" factual obtida através de uma objetividade, enquanto que a ficção, objeto de criação do ficcionista, ficaria restrita em 
narrar eventuais acontecimentos apreendidos por meio da subjetividade do escritor.

A defesa do diálogo entre a história e a literatura teve em Hayden White um dos seus principais expoentes contemporâneos. Ao incursionar pelos terrenos da historiografia e do literário, o historiador estadunidense sublinhou a circunscrição do discurso histórico como uma prática eminentemente narrativa, próxima do discurso ficcional. White reflete, na obra Trópicos do discurso (1994), sobre a necessidade de expansão das fronteiras da história, no que concerne às suas definições e métodos de investigação e escrita, insistindo que a postura de alguns historiadores contemporâneos de manter a história situada no âmbito dos paradigmas científicos do século XIX deve ser refutada, visto que os demais saberes das Humanidades ultrapassaram há muito tempo essa concepção. Por essa razão, White convida aquela historiografia, atrelada às ideias positivistas do século XIX, a abrir-se aos procedimentos críticos que ocasionaram transformações no âmbito da literatura. White defende que a reflexão acerca das relações entre a história e a literatura deve considerar o fato de as duas serem formas narrativas que têm como instrumento comum a representação.

Para Georges Duby, “o historiador conta uma história, uma história que ele forja recorrendo a certo número de informações concretas" (DUBY, 1986, p. 13). Deste modo, percebe-se que a narrativa da história se aproxima do ato de contar engendrado pela arte literária. Nesse sentido, Linda Hutcheon (1991) afirma que anteriormente ao advento da história positivista, a literatura e a história faziam parte da mesma árvore do saber, ambas interpretavam a experiência com o intuito de orientar e elevar o ser humano. A pesquisadora canadense faz a seguinte observação com relação à história e à literatura:

Considera-se que as duas obtêm suas forças a partir da verossimilhança, mais do que a partir de qualquer verdade objetiva. As duas são identificadas como construtos linguísticos, altamente convencionalizadas em formas narrativas e nada transparentes em termos de linguagem ou de estrutura; e parecem ser igualmente intertextuais, desenvolvendo os textos do passado com sua própria textualidade complexa (HUTCHEON, 1991, p. 141).

Segundo Hutcheon, essa interlocução entre literatura e história é um dos traços da narrativa contemporânea, por meio da qual problematiza-se, a partir do texto literário, o discurso historiográfico tido como indiscutível, representativo de uma pretensa "verdade" acabada. Assim, esta prática escritural induz a uma releitura do passado, visto que questiona a história considerada como oficial, desconstruindo o argumento desta, que se fundamenta no binômio verdade/mentira. Para Hutcheon, o que existem são pontos de vista adotados por romancistas e por historiadores sobre um determinado acontecimento. 
A literatura tem desempenhado um papel fundamental dentro dessa ótica de ressignificação histórica. Nessa direção, pode-se dizer que Marcelo Rubens Paiva, em Não és tu, Brasil (1996), representa em sua narrativa um episódio do passado brasileiro pouco conhecido e abordado pelos estudiosos. O referido romance trata-se de uma ficção com elementos de não ficção, que entrelaça a história pessoal do narrador/personagem com os desdobramentos que se sucederam no Vale do Ribeira (região localizada no sudeste do estado de São Paulo e nordeste do estado do Paraná) durante a ditadura militar; mais especificamente no que concerne ao cerco montado pelo Exército a Carlos Lamarca e seus companheiros de Vanguarda Popular Revolucionária (VPR), que pretendiam montar na referida região um campo de treinamento de guerrilha. No posfácio da obra, o autor diz o seguinte:

Este é um livro de ficção com elementos de não ficção. Por ser um romance, não há qualquer preocupação em relacionar as fontes, muito menos em seguir um padrão preestabelecido pelas convenções. Muitas das frases estão sem aspas, seguindo o estilo livre condizente com um romance.

Os fatos referentes à guerrilha do Ribeira e à luta armada no Brasil, assim como os acontecimentos que envolveram o povo do Vale do Ribeira, estão bem próximos da verdade. Como o próprio narrador diz, a história verdadeira nunca será conhecida; muitas testemunhas fundamentais estão mortas e o tema ainda hoje é tabu, especialmente nas Forças Armadas (PAIVA, 1996, p. 291).

A partir das rememorações e peripécias de um narrador/personagem, Marcelo Rubens Paiva promove o entrelaçamento de elementos históricos e ficcionais, recriando (por meio de documentos oficiais do Exército brasileiro, de publicações dos movimentos revolucionários de esquerda da época e de materiais jornalísticos veiculados na imprensa do País) o ambiente sócio-histórico do regime ditatorial e o cerco aos guerrilheiros da Vanguarda Popular Revolucionária, organização comandada por Carlos Lamarca, em 1970. O episódio histórico, conhecido como Guerrilha do Vale do Ribeira, impôs uma surpreendente derrota aos mais de 1500 homens das forças armadas do Brasil que perseguiam apenas cinco revolucionários (Ariston Lucena, Carlos Lamarca, Diógenes Sobrosa de Souza, Gilberto Faria Lima e Yoshitane Fujimori). Mesmo assim, o referido acontecimento é praticamente desconhecido pela maioria dos brasileiros.

Em sua construção estética, Paiva estabelece um intenso diálogo com a história, preenchendo lacunas, estabelecendo uma narrativa polifônica, confrontando posições ideológicas antagônicas, promovendo relações intertextuais com fontes historiográficas e reconfigurando a memória dos difíceis anos de chumbo da ditadura militar.

O modo pelo qual Paiva constrói o romance e dá voz aos seus personagens é 
multiperspectivo, visto que entrelaça representação ficcional com documentos oficiais e material jornalístico, dando à obra um caráter híbrido e plurirrepresentativo, tendo em vista a diversidade de vozes, os intertextos e a inserção fragmentária dos distintos documentos históricos presentes no romance, que propiciam o resgate e a reconstrução de partes de um passado ditatorial pouco conhecido e aprofundado.

\section{POLIFONIA, INTERTEXTUALIDADE E O RESGATE DAS VOZES SILENCIADAS PELA HISTÓRIA EM NÃO ÉSTU, BRASIL}

Mikhail Bakhtin, na obra Problemas da poética de Dostoiévski, empreendeu uma análise acerca dos romances do escritor Fiódor Dostoiévski, com o intuito de questionar os estudos críticos anteriores a respeito das obras do romancista russo. Bakhtin refutou as leituras que enquadravam as narrativas do criador de Os Irmãos Karamazov num plano monológico de análise. Para a teoria bakhtiniana, Dostoiévski foi o criador de um novo subgênero literário, o romance polifônico, cuja característica marcante estaria no fato de que nas obras do referido romancista as vozes que ressoam no texto não se sujeitam a um narrador centralizante (como, em geral, acontece no romance considerado tradicional), pois elas relacionam-se umas às outras em condições de igualdade.

O romance polifônico, para Bakhtin, apresenta diferentes vozes sociais que se defrontam, se entrechocam, manifestando diferentes pontos de vistas sociais sobre um dado objeto. Por meio da análise da obra de Dostoiévski, o teórico russo considerou o texto romanesco como uma prática artística polifônica, articuladora e harmonizadora de vozes plurais (literárias, históricas, sociais, políticas, culturais, etc), as quais, num entrecruzamento incessante, promovem a inter-relação de diferentes ideologias. A reflexão bakhtiniana postula que a representação das personagens no autor de $O$ Jogador é, acima de tudo, a representação de consciências, que não se trata da consciência de um "eu" único e indiviso, mas da interação de distintas consciências que dialogam entre si. No que concerne à criação e importância do romance polifônico, Bakhtin fez a seguinte asserção:

Consideramos a criação do romance polifônico um imenso avanço não só na evolução da prosa ficcional do romance, ou seja, de todos os gêneros que se desenvolvem na órbita do romance, mas, generalizando também na evolução do pensamento artístico da humanidade. Parece-nos que se pode falar francamente de um pensamento artístico polifônico de tipo especial, que ultrapassa os limites do gênero romanesco. Este pensamento atinge facetas do homem e, acima de tudo, a consciência pensante do homem e o campo dialógico do ser, que não se prestam ao domínio artístico se enfocados de 
posições monológicas (BAKHTIN, 2002, p. 273).

A reflexão bakhtiniana considerou que todo texto se constrói como uma multiplicidade de vozes sociais, um mosaico de citações, cuja produtividade textual resulta de um processo de escuta, absorção e réplica de outros textos. A contribuição inovadora do estudo teórico-crítico de Bakhtin conduziu a diferentes maneiras de se ler o texto de ficção, abrindo novas perspectivas para os estudos literários, no que se refere ao diálogo e ao estabelecimento de correlações entre o literário e outros sistemas artísticos, além da interlocução da literatura com outras disciplinas do saber humano, como a história.

Para Bakhtin, "todas as palavras e formas que povoam a linguagem são vozes sociais e históricas, que lhe dão determinadas significações concretas e que se organizam no romance em um sistema estilístico harmonioso" (BAKHTIN, 1998, p. 100). A partir das reflexões bakhtinianas sobre a polifonia no romance, a teórica búlgaro-francesa Julia Kristeva cunhou o termo "intertextualidade" para designar o processo de produção do texto literário. Para Kristeva, por meio da intertextualidade "todo texto é absorção e transformação de outro texto. Em lugar da noção de intersubjetividade, se instala a de intertextualidade, e a linguagem poética se lê, pelo menos, como dupla" (KRISTEVA, 1974, p. 62). De acordo com Kristeva, a palavra literária não é um ponto (no sentido fixo), mas um cruzamento de superfícies textuais, um diálogo de diversas escrituras: do escritor, do destinatário (ou da personagem), do contexto cultural atual ou anterior. No que concerne à importância e contribuição das reflexões de Bakhtin, Kristeva faz a seguinte afirmação:

Introduzindo a noção de estatuto da palavra como unidade minimal da estrutura, Bakhtin situa o texto na história e na sociedade, encaradas por sua vez como textos que o escritor lê e nas quais ele se insere ao reescrevê-las. A diacronia se transforma em sincronia e à luz dessa transformação, a história linear surge como uma abstração; a única maneira que tem o escritor de participar da história vem a ser, então, a transgressão dessa abstração através de uma escritura-leitura (KRISTEVA, 1974, p. 62).

Para Kristeva, o dialogismo bakhtiniano designa a escritura simultaneamente como subjetividade e comunicatividade, ou melhor, como intertextualidade. Face a esse dialogismo, a noção de "pessoa-sujeito da escritura" começa a se esfumar, para ceder lugar a uma outra, a da "ambivalência da escritura". O termo "ambivalência" implica a inserção da história e da sociedade no texto, e do texto na história, o que para o escritor são uma única e mesma coisa. A investigadora búlgaro-francesa ressalta, por meio das ideias de seu estudo teórico, que falando de duas vias que se unem na narrativa, Bakhtin tem em vista a escritura como leitura 
do corpus literário anterior, o texto como absorção e réplica a outro(s) texto(s).

A partir das reflexões bakhtinianas e da (re)leitura promovida por Kristeva no que se refere aos postulados do teórico russo sobre o diálogo entre discursos textuais, observa-se que a intertextualidade pode ser considerada um elemento intrínseco da interlocução entre a literatura e a história, pois tanto a codificação da escritura literária, quanto a do texto histórico adquirem sentido e importância como partes de discursos anteriores. A intertextualidade permite a discussão acerca da noção de contexto estabelecido, gerando uma gama de novos âmbitos e questionando o sentido unívoco e centralizado. Ela tem uma dimensão teórica muito proveitosa quando aplicada às relações interdisciplinares entre a literatura e a história, pois exige o reconhecimento de vestígios textualizados do passado literário e histórico, além da compreensão do tratamento dado a esses vestígios, obrigando-se a admitir não apenas a inevitável textualidade do conhecimento sobre o passado, mas também o valor e a limitação da forma discursiva sobre esse conhecimento.

A intertextualidade pode ser entendida como uma manifestação formal de um desejo de reduzir a distância entre o tempo anterior e o presente do autor/leitor e também de revisitar e reinterpretar o passado dentro de um novo contexto/perspectiva. Como princípio inerente à interlocução entre os discursos da literatura e da história, a intertextualidade aponta, ainda, para o romance contemporâneo como um campo em que a presença do acontecimento histórico figura como matéria nuclear de elaboração artística.

Em Não és tu, Brasil, Marcelo Rubens Paiva deixa evidente ao leitor que a intertextualidade é parte fundamental de sua construção estética, visto que em sua narrativa cita e reproduz diversos textos históricos, como informes, relatórios, manifestos, reportagens, entrevistas, etc. O processo ricamente intertextual de composição fica ainda mais explícito no posfácio do livro, quando o autor cita e agradece arquivos e bibliotecas nas quais realizou pesquisas, além de mencionar claramente referências bibliográficas que utilizou para compor a obra:

Agradeço também aqueles que abriram seus arquivos, especialmente Judith Patarra, Fundação Getúlio Vargas e empresas Jornal do Brasil, Agência Estado, Folha da Manhã e Editora Abril. Agradeço a paciência de bibliotecários da USP, Unicamp, Biblioteca Nacional e Biblioteca da Universidade de Stanford, EUA. Agradeço ainda o Hoover Institute, da Califórnia, que abriu as portas para minha pesquisa. [...]

E é importante ressaltar a colaboração indireta dos autores e instituições: ABREU, Hugo. O outro lado do poder. Rio de Janeiro: Nova Fronteira, 1980.

ALARCON, Rodrigo. Brasil, represión y tortura. Santiago: Orbe, 1971.

ALVES, Márcio Moreira. El despertar de la revolución brasileña. México: 
Diogenes, 1972.

Torturas e torturados. Rio de Janeiro: Empresa Jornalística, 1967.

(PAIVA, 1996, p. 292).

Paiva construiu seu texto de forma multifacetada, justapondo à narração documentos históricos, método que estilisticamente constitui uma estética peculiar, provocando o efeito de chamar a atenção do receptor sempre que algum texto historiográfico é inserido na narrativa, devido à diferenciação no tipo e tamanho da fonte e também no recuo dos parágrafos. Quando o autor insere na narrativa algum trecho documental, sendo ele oficial, jornalístico ou manifesto guerrilheiro, o faz inserindo-o com uma fonte menor e distinta da principal, alternando a escrita das palavras em letras maiúsculas e minúsculas, e citando suas referências. Como exemplo deste procedimento composicional, tem-se o fragmento a seguir:

\author{
DECLARAÇÃO DAS ORGANIZAÇÕES REVOLUCIONÁRIAS \\ BRASILEIRAS COM MOTIVO DA MORTE DE CARLOS LAMARCA \\ setembro de 1971 \\ A morte do comandante Carlos Lamarca foi uma grande perda para a luta \\ revolucionária de nosso povo. Porém, não representa em nenhum momento a \\ derrota que a ditadura militar trata de transparecer na imprensa, nem \\ tampouco uma suspensão da luta que hoje se desenvolve no Brasil. \\ $[\ldots]$ \\ A morte do comandante Lamarca é uma perda irrecuperável, porém não \\ debilita nossa disposição de continuar. \\ ATÉ A VITÓRIA SEMPRE \\ OUSAR LUTAR, OUSAR VENCER \\ assinado: \\ Aliança Libertadora Nacional (ALN) \\ Movimento Revolucionário 8 de Outubro (MR-8) \\ Movimento Revolucionário Tiradentes (MRT) \\ Partido Comunista Brasileiro Revolucionário (PCBR) \\ Vanguarda Popular Revolucionária (VPR) \\ Vanguarda Armada Revolucionária (VAR-Palmares) \\ Ação Popular do Brasil (AP) \\ (PAIVA, 1996, p. 11-12).
}

É a relação intertextual que permite ao leitor - por meio dos documentos históricos e da narração ficcionalizada - revisitar uma parcela do passado sob uma perspectiva múltipla. Importante dizer que não se trata aqui de superposição de um texto sobre o outro. Em nenhum momento os documentos oficiais colhidos por Paiva no processo de elaboração do romance sobrepõem-se às partes ficcionalizadas da obra. Ao contrário, é a relação mútua de influência de um texto sobre o outro, da relação dialógica estabelecida entre eles, que faz com que essa parcela do passado apareça ao leitor de forma mais abrangente, cabendo a este, então, absorvê-la e questioná-la de um ponto de vista crítico, já que o passado - para aquele que não 
o viveu ou até mesmo para aquele que, de certo modo, fez parte dele - é sempre contado por diferentes versões, partes, pedaços, como pontua o narrador-personagem no trecho citado abaixo:

Me encostei na poltrona, olhei o rio e me abri, já que tínhamos toda a tarde, já que ela ocupava com dignidade o posto de uma intrusa curiosa, sempre, pelo passado que regeu aquelas terras. Dei, então, um pedaço do passado, como Mauro deve ter feito, como outros fizeram, os empregados, os eldoradenses, para que ela completasse, com cada frase, toda a história que não viveu, mas cujos fantasmas rondam e instigam (PAIVA, 1996, p. 89).

Fica nítido, a partir da ótica do narrador-personagem na passagem acima, que o passado é fragmentado e composto de pedaços, nos quais cada qual, que vivenciou a temporalidade pretérita, deposita uma parcela da história que será completada pelo receptor/leitor. Esta forma de se encarar a história confronta o ideal positivista, que almejava homogeneizá-la e totalizá-la. Na narrativa de Paiva, a retomada do passado é feita por um conjunto de fios trançados a partir de diferentes perspectivas, que cose na rede histórica dos acontecimentos as distintas versões dos fatos.

Importante salientar que a história tradicional se preocupava em narrar apenas os "grandes feitos", realizados pelos "homens notáveis" ou pelas "nações mais importantes". De acordo com Edson Luis de Almeida Teles, uma história que pretenda dar conta efetivamente dos acontecimentos, deve voltar-se para o passado que não foi transmitido pela tradição histórica, isto é, para o passado dos oprimidos e derrotados politicamente:

A história busca o passado fragmentado e não transmitido pela tradição, composto pelas memórias esquecidas, as que somente podem ser contadas pelos que pertenciam às causas políticas derrotadas ou minoritárias. [...] Ao recorrermos à memória dos relatos e testemunhos das épocas passadas, estamos transformando essas narrativas em história, fazendo com que um amontoado de fatos ganhe sentido. [...] Sua importância não está em apresentar uma imagem do passado, tirando sua autenticidade, mas em transformá-lo em uma experiência política única que possa renovar o futuro com seu reconhecimento no presente. Um sentido histórico só pode ser apreendido se o acontecimento passado for interrogado (TELES, 2004, s/p).

A partir da citação acima, pode-se dizer que Paiva, em Não és tu, Brasil, trouxe ao debate uma leitura histórica diferente da ditadura militar brasileira, não pautada somente a partir de uma perspectiva tradicional, isto é, baseada apenas em documentos oficiais e em fontes estatais, mas também sob a ótica dos derrotados, já que insere em sua narrativa, por exemplo, fragmentos de entrevistas concedidas pelos guerrilheiros aos meios de comunicação 
da época. $\mathrm{O}$ excerto a seguir é um exemplo disso:

\author{
ENTREVISTA COM CARLOS LAMARCA \\ publicada na revista chilena \\ Punto Final \\ julho de 1970 \\ P: Existem condições para a guerrilha rural no Brasil? \\ R: Sim, existem, não somente no Brasil como em toda a América Latina. É \\ no campo onde a exploração capitalista é mais desumana, onde está o elo \\ frágil do sistema, onde a repressão tem sido feroz. Existe todo um passado \\ de luta e de organização do trabalhador rural que a classe dominante omite \\ em nossa história. \\ P: Como foi a repercussão na população local da guerrilha do Vale do \\ Ribeira? \\ R: Ficamos satisfeitos ao comprovar a receptividade e a capacidade de \\ entender nossos objetivos por parte do trabalhador rural. A repressão \\ percebeu que começamos a ganhar apoio da população. Prendeu e assassinou \\ um jovem casal camponês, evacuou a população da região e bombardeou a \\ área. Complementou o terrorismo com rajadas de metralhadoras a esmo \\ dentro da mata e voos rasantes sobre casebres ainda habitados (PAIVA, \\ 1996, p. 190-191).
}

O fragmento acima evidencia um dos aspectos principais da narrativa de Paiva: dar voz àqueles que foram silenciados pela história tradicional. Ao colocar em seu texto uma entrevista verídica concedida por Carlos Lamarca a um periódico chileno, o romancista brasileiro adota uma perspectiva diferente daquela veiculada pelo discurso oficial, denunciando a repressão da ditadura em relação aos camponeses do Vale do Ribeira e invertendo o polo dos considerados terroristas: os militares ao invés dos guerrilheiros. Em outros momentos do texto, observa-se a ratificação deste olhar crítico em relação aos militares, agentes da repressão que aterrorizavam a população:

\title{
AO POVO BRASILEIRO
}

setembro de 1970

Enquanto estávamos na região próxima de Sete Barras, assistíamos aos roubos que a tropa fazia nas plantações, e às humilhações por que passavam os trabalhadores da região. O Exército demonstrou capacidade apenas de aterrorizar a população. Aprisionou um casal que tentou nos ajudar, torturouos e matou-os, e para justificar esses crimes, passaram com uma viatura sobre os cadáveres mutilados, para dar a impressão de que haviam sido atropelados acidentalmente.

\section{OUSAR LUTAR \\ OUSAR VENCER \\ VPR}

(PAIVA, 1996, p. 213-214).

Pode-se dizer que, a partir desses relatos inseridos no romance, é dirigido um pouco 
de luz sobre uma parte do passado que foi lançada no esquecimento após a reabertura democrática do Brasil. Este passado é recuperado, ao longo da narrativa de Paiva, por meio das vozes silenciadas pela história dita "tradicional”. Linda Hutcheon, em Poética do pósmodernismo, aponta alguns traços da narrativa pós-moderna, cujo papel ideológico, segundo ela, posiciona-se a favor dessas vozes omitidas e marginalizadas:

Entretanto, a arte e a teoria pós-modernistas têm reconhecido de forma autoconsciente seu posicionamento ideológico no mundo, e têm sido estimuladas a fazê-lo, não apenas como reação a essa insultuosa acusação de trivialidade, mas também por aqueles ex-cêntricos, que antes eram silenciados (HUTCHEON, 1991, p. 228).

O narrador de Não és tu, Brasil estabelece um diálogo com o leitor, e se posiciona também ao lado dessas vozes que são silenciadas e esquecidas pelos anais da história. No trecho a seguir, é importante observar o posicionamento do narrador-personagem, que não está preocupado com uma suposta "verdade" da versão oficial, mas sim com uma verdade plural, obtida pelo testemunho de diversas vozes:

Em Eldorado, todo mundo se lembra de Fujimori. Era Lamarca e Fujimori, o comandante e o Samurai. Tem gente daqui de Eldorado que jura que Fujimori atravessou a praça no dia do tiroteio com duas metralhadoras, aqui, ó, uma em cada braço, calmo, tomou a cidade, zen, desafiando a Força Pública. Te parece o quê?, cena daqueles filmes de Hong Kong que eram exibidos. Nada disso; eu estava lá, nenhum guerrilheiro atravessou a praça. Ou tudo isso é verdade, não interessa. É verdade daqui, não dos anais. São as testemunhas silenciadas pela História (PAIVA, 1996, p. 103).

Preocupado em criar um romance que esteticamente não apresentasse ao leitor um protagonista onisciente, transmissor de informações supostamente precisas e incontroversas ou seja, que veiculasse apenas uma visão sobre os acontecimentos narrados -, Paiva se propõe a recontar os acontecimentos do Vale do Ribeira valendo-se das múltiplas vozes que, em certa medida, os vivenciaram parcialmente. Uma dessas vozes é a dos militares, considerada oficial, presente nos documentos e divulgada em textos jornalísticos da época, as quais classificavam Carlos Lamarca como subversivo, doutrinador, terrorista, comunista, fanático, conforme ilustram os excertos que se seguem:

CONSELHO PERMANENTE DA SEGUNDA AUDITORIA DE GUERRA DE SÃO PAULO

julho de 1981

Segundo autos do processo, o agricultor Jorge Batista da Rosa informara às 
autoridades, durante operações contra guerrilhas no Vale do Ribeira, que havia sido procurado por um elemento subversivo que o queria doutrinar. No álbum de fotos, o agricultor identificou o ex-capitão Carlos Lamarca (PAIVA, 1996, p. 186, grifos nossos).

$[\ldots]$ ENTREVISTA AO JORNAL FOLHA DA TARDE

Concedida pelo coronel Erasmo Dias agosto de 1979

Em busca de contato, nossos grupos, ao enfrentar o Lamarca, realmente chegaram a debandar. Houve debandada geral. Quando realmente se percebeu que na verdade era o Lamarca, houve uma espécie de pânico geral. Nosso grupo não estava preparado para enfrenta-lo. São coisas que acontecem. O terrorista é alguém que, pelo livre arbítrio, por seu fanatismo, até por seu masoquismo, abraça essa luta inglória de um homem ideologicamente condicionado, emulado, fanático. Nosso soldado é o homem comum. Há que se entender que, numa luta dessas, o terrorista comunista sempre terá vantagem (PAIVA, 1996, p. 194).

Em outras partes da narrativa, há a exibição de documentos que foram divulgados pelo Exército brasileiro da época, nos quais percebe-se claramente o intuito de construir um discurso que visava colocar a opinião pública contra os guerrilheiros, disseminando a ideia de que eram ladrões e assassinos, que perturbavam a ordem e a tranquilidade da "família" nacional:

\footnotetext{
NOTA DO MINISTÉRIO DO EXÉRCITO

maio de 1971

O Codi, Centro de Operações de Defesa Interna, desenvolve trabalho para erradicar o terrorismo e oferecer tranquilidade à população, e muitos bandidos foram recuperados e, hoje, em liberdade, encontram-se em fase de reintegração na sociedade; contra aqueles que acirradamente recebem ajuda do exterior (áreas comunistas), roubam e assassinam brasileiros, é que as autoridades agem com energia, visando a salvaguarda da família e a garantia do desenvolvimento nacional (PAIVA, 1996, p. 242).
}

O narrador de Não és tu, Brasil questiona, em diversos momentos do texto, a versão oficial divulgada pelo governo e pela imprensa acerca dos acontecimentos da época. Em um dos trechos da narrativa, ele diz: "O que os jornais publicaram? Variações da nota oficial" (PAIVA, 1996, p. 208). Problematiza também a aliança entre o Estado e uma parte significativa da imprensa, que resultou na manipulação da opinião pública, organizando farsas e forjando depoimentos e reportagens contrárias aos guerrilheiros, sempre visando perseguir e depreciar a imagem destes:

Entrevista? Farsa. Um depoimento forjado; eu já espero o suficiente para notar a diferença. Comparar a reportagem da Manchete com a da Folha. As mesmas palavras. Uma nota oficial rescrita (PAIVA, 1996, p. 244). 
$[\ldots]$

O inimigo o regime, o sistema. Não era uma guerra particular entre grupos guerrilheiros e grupos paramilitares, VPR versus DOI-Codi, ALN versus DOPS. Para a repressão profissionalizada, a guerra era, sim, particular. E parte da imprensa obediente dava um colorido mais nobre à causa militar: mocinhos versus bandidos, defensores do progresso versus fanáticos, a família versus terroristas em calças de veludo e óculos psicodélicos (PAIVA, 1996, p. 247).

Assim como postula Hutcheon em relação à narrativa pós-moderna, o narrador de Paiva coloca-se, principalmente na parte final do texto, ao lado dos ex-cêntricos e oprimidos, que antes eram silenciados, tidos como marginais pelo discurso oficial da história. Deste modo, ele denuncia a repressão feita pelo governo ditatorial, que perseguiu e assassinou muitos guerrilheiros, inclusive o líder da VPR, Carlos Lamarca:

Nova fase da repressão: com a quantidade de presos trocados nos sequestros, passaram a eliminá-los, por vezes desaparecendo com os corpos. Simples, não? Em média, a vida útil de um guerrilheiro era de um ano. Lamarca durou três. Dos que combateram no Vale do Ribeira, era o único ainda livre no Brasil (PAIVA, 1996, p. 214).

[...]

A confirmação de que Anselmo era um traidor: o massacre de toda a VPR do Recife, vinte e cinco militantes mortos (PAIVA, 1996, p. 249).

[...]

TERROR CHEGA AO FIM

nota oficial da Polícia Militar de SP

setembro de 1971

Ex-terrorista Carlos Lamarca, traição e crimes pontilharam sua vida. O terrorista Carlos Lamarca morreu na tarde do dia 17 de setembro de 1971 ao reagir à voz de prisão dada por uma equipe de segurança na região de Pintada (PAIVA, 1996, p. 265).

O último fragmento da citação é uma nota que foi publicada pelos militares anunciando a morte de Carlos Lamarca. A esse documento oficial - que mais uma vez classifica o líder guerrilheiro como criminoso, traidor da pátria, terrorista -, o narrador de Paiva contrapõe com a sua visão a respeito desse personagem, o qual foi silenciado pela história tradicional. Ele menciona que há uma dívida da historiografia oficial com Lamarca, uma lacuna que ele tenta preencher com a sua narrativa:

A História em dívida. A superficialidade das biografias rápidas e a imprensa em simbiose com os clichês deixaram de citar sua grande obra, ou, para usar, sua maior ação revolucionária: Lamarca mudou, quando poucos mudavam; viu longe, quando era impossível enxergar; foi um visionário sob fogo cruzado. [...] Foi lutar? Foi. Como? Foi ensinar, escrever, propor, convencer, discutir, aprender, conhecer o Brasil que contradisse as teorias 
revolucionárias e não aderiu. Foi ouvir do povo as lições de resistência [...] Não está nos livros [...]. A verdade não está nos provérbios, mas nos ditos populares, não são os feitos das grandes revoluções que mudam o mundo, mas as lendas dos pequenos anônimos [...] Enxergava além dos escritos, palavras, teoria, além dos mitos e da fama vazia. Lamarca via além da profecia. Entregou-se ao sacrifício. É o herói que soube perder (PAIVA, 1996, p. 283-284).

Conforme evidenciado neste artigo, nota-se claramente, ao longo da obra Não és tu, Brasil, a polifonia contida na narrativa de Paiva a respeito da luta entre os militares e os guerrilheiros da VPR, no tempo da ditadura no Brasil. Há, no âmbito da narração, a veiculação de uma série de referências intertextuais, que contribuem para a ampliação da compreensão acerca do evento histórico representado, pois vozes marginalizadas que participaram ou que testemunharam o referido conflito são inseridas no âmbito da disputa discursiva, para que se tenha uma leitura e um registro histórico mais adequado, plural e representativo.

\section{REFERÊNCIAS}

BAKHTIN, Mikhail. Questões de literatura e de estética: a teoria do romance. Trad. de Aurora Fornoni Bernadini et al. São Paulo: Editora UNESP, 1998.

BAKHTIN, Mikhail. Problemas da poética de Dostoiévski. Trad. de Paulo Bezerra. Rio de Janeiro: Forense Universitária, 2002.

DUBY, Georges et al. História e nova história. Trad. de Carlos da Veiga Ferreira. São Paulo: Teorema, 1986.

HUTCHEON, Linda. Poética do pós-modernismo: história, teoria, ficção. Trad. de Ricardo Cruz. Rio de Janeiro: Imago, 1991.

KRISTEVA, Julia. A palavra, o diálogo, o romance. In: Introdução à semanálise. Trad. de Lúcia Helena França Ferraz. São Paulo: Perspectiva, 1974, p. 61-90.

PAIVA, Marcelo Rubens. Não és tu, Brasil. São Paulo: Mandarim, 1996.

TELES, Edson Luis de Almeida. Passado, memória e história: o desejo de atualização das palavras e feitos humanos. In: Revista Urutágua. Ano I, n. 3, UEM/Maringá, dez. 2004. Disponível em: http://www.urutagua.uem.br/03teles.htm. Acesso em: 15 de abril de 2020.

WHITE, Hayden. Trópicos do discurso: ensaios sobre a crítica da cultura. Trad. de Alípio Correia de Franca Neto. São Paulo: EDUSP, 1994. 